\title{
POTENCIALIDADES DAS ATIVIDADES EXPERIMENTAIS NO ENSINO DE QUÍMICA
}

\author{
POTENCIAL OF EXPERIMENTAL ACTIVITIES IN CHEMISTRY EDUCATION
}

\author{
Diego Marlon Santos \\ Universidade Estadual do Paraná, marlonquimica29@gmail.com \\ Lucila Akiko Nagashima \\ Universidade Estadual do Paraná, lucilanagashima@uol.com.br
}

\section{Resumo}

As práticas pedagógicas como as atividades experimentais são fundamentais no ensino de química, pois são uma forma eficiente na disseminação dos conteúdos, e apoio na construção do conhecimento, motivando o aluno ao desejo pelo saber, evitando a rotina de um ensino tecnicista. Este trabalho foi realizado de acordo com os pressupostos da pesquisa qualitativa com alunos do $3^{\circ} \mathrm{A}$ e $\mathrm{B}$ do Ensino Médio, com o objetivo de investigar a opinião dos alunos a respeito da atividade experimental sobre extração de óleo essencial do cravo-da-índia, cujo levantamento foi realizado por meio de questionário. Com relação à metodologia, para que seja ampliada a eficiência do processo de aprendizagem, as atividades foram conduzidas com amplo questionamento por parte dos alunos, incentivando-os a buscar explicações para os fenômenos estudados. Foi observado que a maior parte dos alunos mostrou interesse deixando-os motivados no processo de ensino e aprendizagem, por se tratar de uma metodologia que oferece ao aluno mais chances de observar, analisar e discutir em grupos os resultados alcançados. No entanto, é preciso considerar que o importante é o desafio cognitivo que o experimento oferece e não o simples manuseio de equipamentos e vidrarias.

Palavras-chave: Ensino de Química, Experimentação, Óleos Essenciais.

\section{Abstract}

Pedagogical practices such as experimental activities are fundamental in the teaching of chemistry, since they are an efficient way in disseminating the contents, and support in the construction of knowledge, motivating the student to desire for knowledge, avoiding the routine of a technicalist teaching. This work was carried out according to the assumptions of the qualitative research with $3 \mathrm{rd}$ and 5th grade students, with the objective of investigating the students' opinion about the experimental activity on the extraction of essential oil of clove, was performed by means of a questionnaire. Regarding the methodology, in order to increase the efficiency of the learning process, the activities were conducted with ample questioning by the students, encouraging them to seek explanations for the studied phenomena. It was observed that most of the students showed an interest 
leaving them motivated in the process of teaching and learning, because it is a methodology that offers the student more chances to observe, analyze and discuss in groups the results achieved. However, we must consider that the important thing is the cognitive challenge that the experiment offers and not the simple handling of equipment and glassware.

Keywords: Teaching of Chemistry, Experimentation, Essential Oils.

\section{Introdução}

O ensino experimental tem sido considerado um recurso útil para promover a aprendizagem de ciências. Pesquisas revelam, entretanto, que muitos professores apresentam uma visão simplista da experimentação, imaginando ser possível "comprovar a teoria no laboratório"; ou que a partir do laboratório se possa chegar à teoria. Desta forma, pode-se considerar que pouco contribuirá para a aprendizagem significativa (ZANON; SILVA, 2000).

O ensino tradicional merece muitas críticas, pois refere-se à ação passiva do aprendiz que frequentemente é tratado como mero ouvinte das informações que o professor expõe. Tais informações, quase sempre, não se relacionam aos conhecimentos que os estudantes já possuem e construíram ao longo de sua vida. E quando não há relação entre o que o aluno já sabe e aquilo que ele está aprendendo, a aprendizagem não é significativa.

As atividades práticas são uma forma de trabalho do professor, e querer utilizá-las, ou não, é uma decisão pedagógica que não depende apenas da boa vontade do docente, seu preparo ou condições dadas pela escola. Os professores, ao decidirem como desenvolver suas aulas, realizam julgamentos pessoais sobre como devem agir, avaliando crenças, valores e conhecimentos adquiridos na formação e no exercício profissional. Se o professor valoriza as atividades práticas e acredita que elas são determinantes para a aprendizagem de Ciências, possivelmente buscará meios de desenvolvê-las na escola e de superar eventuais obstáculos.

Neste contexto, as atividades práticas permitem aprendizagens que a aula teórica, apenas, não proporciona, sendo compromisso do professor, e também da escola, dar esta oportunidade para a formação do aluno. Nem sempre os professores tomam estas decisões de forma consciente, podendo ser levados a repetir a forma de ensino que vivenciaram quando alunos ou desenvolvida por outros professores. A forma de agir dos professores se deve à aprendizagem de modos de ação tradicionalmente aceitos e realizados por seus pares na socialização da profissão, em grande parte realizada na própria escola (TARDIF, 2002). Os professores, ao deixarem de utilizar atividades práticas, podem estar incorporando formas de ação presentes historicamente no ensino, pautado pela abordagem tradicional, sem maiores reflexões sobre a importância da prática na aprendizagem das Ciências.

Como defendem Carrascosa et al. (2006), a atividade experimental constitui um dos aspectos-chave do processo de ensino-aprendizagem de ciências. Portanto, à medida que se planejam experimentos com os quais é possível estreitar o elo entre 
motivação e aprendizagem, espera-se que o envolvimento dos alunos seja mais vívido e, com isso, acarrete evoluções em termos conceituais.

Portanto, se uma aula experimental for organizada diante de uma situação problema, e estiver direcionada para a sua resolução, poderá contribuir para o impulsionar o raciocínio lógico do estudante sobre a situação e apresentar argumentos na tentativa de analisar os dados e apresentar uma conclusão plausível. Se o estudante tiver a oportunidade de acompanhar e interpretar as etapas da investigação, ele possivelmente será capaz de elaborar hipóteses, testá-las e discuti-las, aprendendo sobre os fenômenos estudados e os conceitos que os explicam, alcançando os objetivos de uma aula experimental, a qual privilegia o desenvolvimento de habilidades cognitivas e o raciocínio lógico.

Hofstein e Lunetta (2003), em uma extensa revisão bibliográfica referente a atividades de laboratório, enfatizam que a abordagem investigativa implica em, entre outros aspectos, planejar investigações, usar montagens experimentais para coletar dados seguidos da respectiva interpretação e análise, além de comunicar os resultados. Tal enfoque propicia aos alunos libertarem-se da passividade de serem meros executores de instruções, pois busca relacionar, decidir, planejar, propor, discutir, relatar, entre outras, ao contrário do que ocorre na abordagem tradicional.

Dessa forma, no Brasil, as atividades práticas são consideradas uma forma de favorecer a consecução dos objetivos propostos pelos Parâmetros Curriculares Nacionais (PCN) para o ensino de Ciências. Nesse sentido, os PCN de Ciências Naturais indicam que as atividades experimentais são procedimentos fundamentais para o ensino da área que permitem a investigação, a comunicação e o debate de fatos e ideias, possibilitados pela observação, experimentação, comparação, estabelecimento de relações entre fatos ou fenômenos. Do mesmo modo, os PCN também valorizam atitudes que, na ótica do presente estudo, podem ser trabalhadas nas atividades práticas, como: o incentivo à curiosidade, o respeito à diversidade de opiniões, a persistência na busca de informações e de provas obtidas por meio de investigação (BRASIL, 2000).

Nessa perspectiva, a observação e a experimentação são indicadas pelos PCN como estratégias didáticas que auxiliam na obtenção de informação, as quais devem contemplar fontes variadas, como a leitura de textos informativos e projetos desenvolvidos preferencialmente em um contexto de problematização.

Além disso, os Parâmetros Curriculares Nacionais - PCN (1998) enfatizam que é muito importante que as atividades não se limitem a nomeações e manipulações de vidrarias e reagentes, fora do contexto experimental. É fundamental que as atividades práticas tenham garantido o espaço de reflexão, desenvolvimento e construção de ideias, ao lado de conhecimentos de procedimentos e atitudes. Possobom et al. (2002) defendem um modelo alternativo, denominado modelo cognitivo, no qual os educadores levantam problemas do cotidiano (questões reais) para que os alunos busquem as soluções. Mesmo que a resposta não seja satisfatória para o professor, não se deve descartar o fato de que o aluno tenha raciocinado para chegar à conclusão. Afirmam os autores: é preciso tentar conhecer como a criança estava pensando (o que a leva a chegar a conclusões diferentes das nossas), como ela está representando as ideias para si. 
As Diretrizes Curriculares para o Ensino de Química do Estado do Paraná (PARANÁ, 2009) diz que as atividades experimentais para o ensino médio contribuem na apropriação do conhecimento químico, e resulta do contato do aluno com o objeto de estudo. Esse contato deve ser planejado, organizado e dirigido pelo professor numa relação dialogada e a experimentação deve conduzir o aluno a refletir sobre os conceitos envolvidos, dando significado à ciência, permitindo assim uma participação mais efetiva no processo de aprendizagem, rompendo a ideia tradicional de experimentação.

As recomendações explicitadas nestas diretrizes consideram a experimentação como um instrumento que favorece a apropriação efetiva do conceito, enfatizando a problematização como ponto de partida para a construção dos conhecimentos. Desta forma, essa experimentação deve orientar o aluno a pensar, a refletir sobre os conhecimentos que está sendo adquirido, ou seja, a atividade experimental deve envolver o aluno e auxiliá-lo na aprendizagem.

Mesmo com todas estas recomendações já discutidas, de modo geral, alunos e professores tendem a uma visão simplista e tradicional sobre experimentação, focando na demonstração de teorias estabelecidas. Isso faz com que o processo de aprendizagem se torne um fenômeno de demonstração ou comprovação de teorias. Assim, Galiazzi (2004) declara que:

não é novidade afirmar que, em geral, professores e alunos de cursos de Química têm uma visão simplista sobre a experimentação. Muitas dessas visões pessoais estão cunhadas pelo empirismo do observar para teorizar e por isso não causou surpresa que muitos dos relatos de aulas com atividades experimentais estivessem alicerçados sobre essas compreensões. Parece-nos que isso aponta para uma questão importante a considerar no planejamento de atividades experimentais, que é a possibilidade de enriquecer o conhecimento sobre a natureza da ciência, pois esse conhecimento influencia a aprendizagem dos estudantes na atividade experimental (GALIAZZI, 2004, p. 327).

Chalmers (1993) afirma que o laboratório pode proporcionar excelentes oportunidades para que os estudantes testem suas próprias hipóteses sobre fenômenos particulares, para que planejem suas ações, e as executem, de forma a produzir resultados dignos de confiança. Reforça ainda que é importante que os professores enfatizem as diferenças entre os experimentos realizados no laboratório escolar, com fins pedagógicos, e a investigação realizada por cientistas.

Enfatiza-se, mais uma vez, que a simples transmissão de informações não é suficiente para que os alunos elaborem suas ideias de forma significativa. É imprescindível que o processo de ensino-aprendizagem decorra de atividades que contribuam para que o aluno possa construir e utilizar o conhecimento (BRASIL, 2002, p. 93).

O professor pode considerar, em aulas expositivas, as descobertas dos aprendizes para trabalhar significativamente os conteúdos pretendidos, pois ao trabalhar com as dificuldades e explicações dos alunos ao fenômeno, ele aliará as concepções prévias aos novos conhecimentos. Não se trata de trabalhar a química que só existe no livro e para a escola. Ao utilizar a experimentação, associando os conteúdos curriculares ao que o educando vivenciou, o educador trabalhará de forma contextualizada, pois não é o 
problema proposto pelo livro ou a questão da lista de exercício, mas os problemas e as explicações construídas pelos atores do aprender diante de situações concretas.

A experimentação pode ser utilizada para demonstrar os conteúdos trabalhados, mas utilizar a experimentação na resolução de problemas pode tornar a ação do educando mais ativa. No entanto, para isso, é necessário desafiá-los com problemas reais; motivá-los e ajudá-los a superar os problemas que parecem intransponíveis; permitir a cooperação e o trabalho em grupo; avaliar não numa perspectiva de apenas dar uma nota, mas na intenção de criar ações que intervenham na aprendizagem (LUCKESI, 2003).

Neste sentido, é importante considerar que ela, por si só, não assegura a produção de conhecimentos químicos de nível teórico-conceitual significativos e duradouros, mas cumpre papel essencial, ajudando no desenvolvimento de novas consciências e de formas mais plenas de vida na sociedade e no ambiente.

Com isso, supera-se a visão linear, alienada e alienante da Química e do seu ensino na medida em que os estudantes são interativamente envolvidos em discussões teóricas relativas a situações reais, sobre as quais eles têm o que falar, na direção da produção de novas interpretações e explicações, dinâmicas, deliberadas, plurais e sistemáticas, pela intermediação essencial de novas linguagens, teorias e saberes disponibilizados pelo professor de Química (SILVA; ZANON, 2000).

$\mathrm{Na}$ abordagem conceitual do conteúdo químico, considera-se que a experimentação favorece a apropriação efetiva do conceito e "o importante é a reflexão advinda das situações nas quais o professor integra o trabalho prático na sua argumentação" (AXT, 1991, p. 81). Na proposta de Axt, a experimentação deve ser uma forma de problematizar a construção dos conceitos químicos, sendo ponto de partida para que os alunos construam sua própria explicação das situações observadas por meio da prática experimental. Desse modo, os aprendizes são levados a desenvolver uma explicação provável que se aproximada dos conceitos e teorias científicas pelos docentes, permite uma melhor compreensão da cultura e prática científica na reflexão de como são construídos e validados os conceitos cientificamente aceitos. Isso possibilita aos alunos uma participação mais efetiva no processo de sua aprendizagem, rompendo com a ideia tradicional dos procedimentos experimentais como receitas que devem ser seguidas e que não admitem o improviso, a modificação e as explicações prováveis do fenômeno estudado.

Para tanto é necessário que a atividade experimental seja problematizadora do processo ensino-aprendizagem, sendo apresentada como recurso na construção do conhecimento nas aulas de ciências, e não como ilustrativo dos conceitos já expostos (forma tradicional da abordagem experimental). Esses fundamentos buscam dar sentido aos conceitos químicos, de modo que se torna muito importante a experimentação na atividade pedagógica. Entretanto, não são necessários materiais laboratoriais específicos. De acordo com Rosito (2003),

[...] muitos professores acreditam que o ensino experimental exige um laboratório montado com materiais e equipamentos sofisticados, situando isto como a mais importante restrição para o desenvolvimento de atividades experimentais. Acredito que seja possível realizar experimentos 
na sala de aula, ou mesmo fora dela, utilizando materiais de baixo custo, e que isto possa até contribuir para o desenvolvimento da criatividade dos alunos. Ao afirmar isto, não quero dizer que dispenso a importância de um laboratório bem equipado na condução de um bom ensino, mas acredito que seja preciso superar a ideia de que a falta de um laboratório equipado justifique um ensino fundamentado apenas no livro texto [...] (ROSITO, 2003, p. 206).

Corroborando esta tese, Nanni (2004) também reforça que diferentemente do que muitos possam pensar, não é preciso haver laboratórios sofisticados, nem ênfase exagerada no manuseio de instrumentos para a compreensão dos conceitos. $O$ experimento deve ser parte do contexto de sala de aula e seu encaminhamento não pode separar a teoria da prática, num processo pedagógico em que os alunos se relacionem com os fenômenos vinculados aos conceitos químicos a serem formados e significados na aula. $O$ autor ainda destaca que a importância da abordagem experimental está no seu papel investigativo e na sua função pedagógica de auxiliar o aluno na explicitação, problematização, discussão, enfim, na significação dos conceitos científicos.

Muito embora tenha discutido que a falta de laboratório não é a principal adversidade para a não realização das atividades experimentais, essa ausência, enquanto uma situação-limite precisa ser superada. Uma das formas de enfrentar a carência de laboratórios é planejar experimentos com materiais alternativos e de baixo custo e que possam ser realizados em sala de aula.

Gonçalves e Marques (2006) têm afirmado que os docentes que percebem a possibilidade de inserir a experimentação no ensino mesmo na ausência de laboratórios, parecem avançar no processo de alcance de uma consciência máxima possível/consciência crítica. Ou seja, esses profissionais, provavelmente perceberam de forma crítica a "situação-limite" e, por isso, agem para superá-la e concretizar o inédito viável.

Segundo Schnetzler (2002) as atividades experimentais realizadas no laboratório ou na sala são relevantes quando caracterizadas pelo seu papel investigativo e sua função pedagógica em auxiliar o aluno na compreensão de fenômenos. Especificamente no ensino de química, a experimentação deve contribuir para a compreensão de conceitos químicos e como afirma Fonseca, (2001), o trabalho experimental deve estimular o desenvolvimento conceitual, fazendo com que os estudantes explorem, elaborem e supervisionem suas ideias, comparando-as com a ideia científica, pois só assim elas terão papel importante no desenvolvimento cognitivo.

No entanto, é preciso argumentar que para a realização de uma aula prática, diversos fatores precisam ser considerados: as instalações da escola, o material e os reagentes requeridos e, principalmente, as escolhas das experiências. Estas precisam ser perfeitamente visíveis, para que possam ser observadas pelos alunos; precisam não apresentar perigo de explosão, de incêndio ou de intoxicação, para a segurança dos jovens; precisam ser atrativas para despertar o interesse dos mais indiferentes; precisam ter explicação teórica simples, para que possam ser induzidas pelos próprios alunos.

Diante do que foi exposto, este trabalho tem como objetivo apresentar uma pesquisa qualitativa sobre percepções dos alunos do Ensino Médio a respeito de 
atividades experimentais de Química, em uma escola pública da cidade de Paranavaí, Paraná.

\section{Materiais e Métodos}

A abordagem deste artigo está centrada nas informações sobre as potencialidades das atividades experimentais no ensino de química, como a técnica de extração de óleo essencial do cravo-da-índia. A pesquisa foi realizada em 2014 envolvendo um grupo de 60 alunos matriculados na terceira série $(A$ e $B$ ) do Ensino Médio do Colégio Estadual Enira Moraes Ribeiro - EFMP, situada no município de Paranavaí, Paraná.

Desta maneira, o trabalho foi realizado de acordo com os pressupostos da pesquisa qualitativa, com a intenção de investigar qual a opinião dos alunos do ensino médio a respeito da atividade experimental. No questionário foram abordadas questões específicas sobre a contribuição da atividade experimental - extração de óleos essenciais - para a aprendizagem na disciplina de química.

Foram realizados os seguintes questionamentos:

1) $O$ que você acha das aulas experimentais para o desenvolvimento dos conteúdos no ensino de química?

2) Você acredita que a aula experimental sobre extração de óleo essencial a partir do cravo-da-índia pode contribuir para alavancar uma aprendizagem dos conteúdos da disciplina de química?

A atividade de extração do óleo essencial do cravo-da-índia foi efetuada por meio do sistema de destilação por arraste de vapor, seguida de evaporação e obtenção de essência, através do evaporador rotativo.

$\mathrm{Na}$ etapa de pesagem e preparo em solução aquosa, pesou-se em uma balança analítica 17,8 g de cravo da índia e, numa proveta mediu-se $100 \mathrm{~mL}$ de água destilada, posteriormente adicionou-se a amostra de cravos em um balão volumétrico. Na etapa seguinte, a de destilação, montou-se um sistema de destilação (Figura 1) com o auxílio de um suporte universal com garra de fixação para o condensador, ligado a um balão de fundo redondo por uma cabeça de destilação, com um termômetro. Para apoio do balão, usou-se uma manta aquecedora e como sistema de recepção para a solução destilada, um erlenmeyer. 


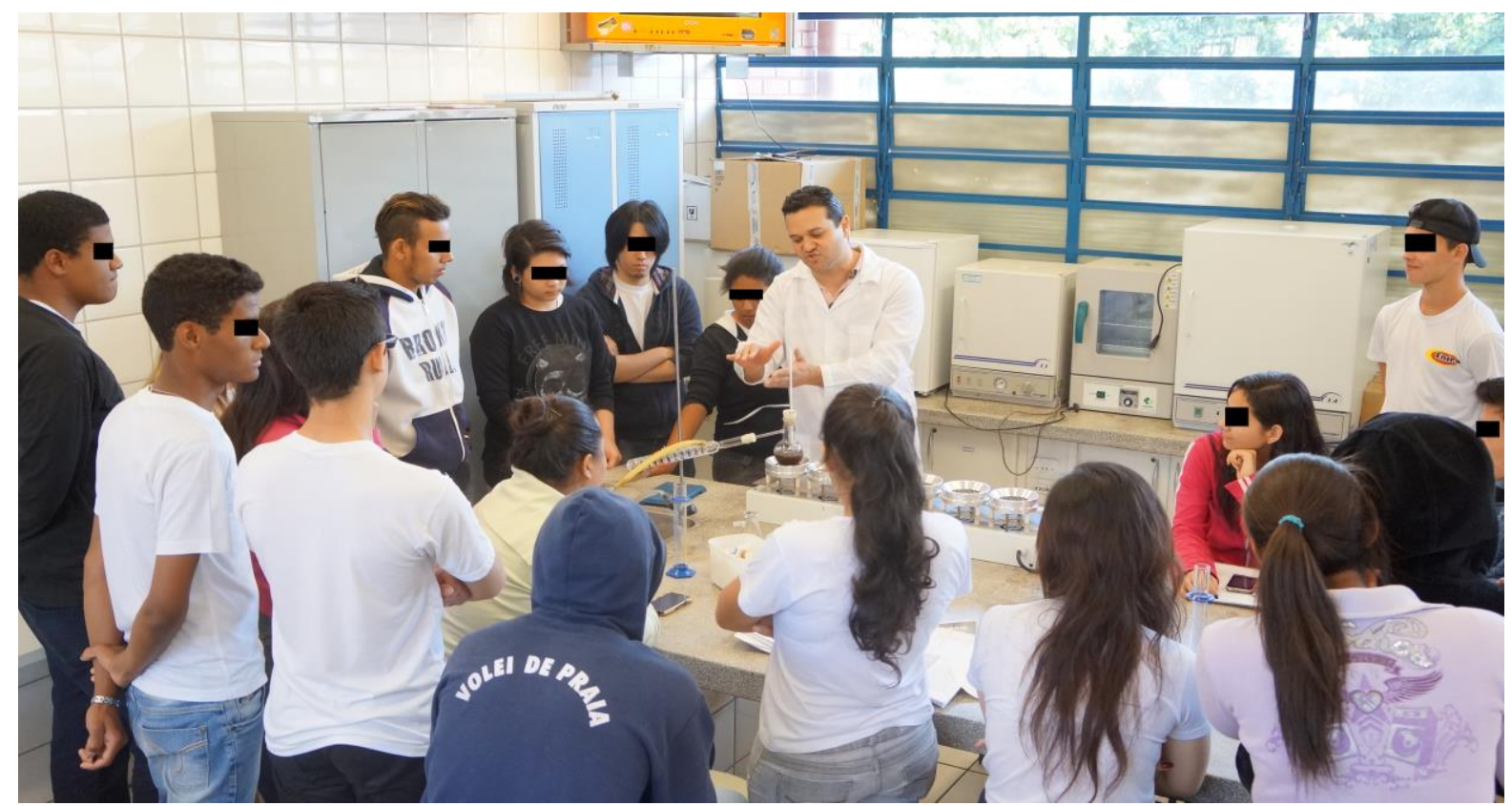

Figura 1 - Alunos do 3ำ A do Ensino Médio prestando atenção na explicação sobre o funcionamento do sistema de destilação.

Fonte: Autor

Ainda nessa etapa, transferiu-se a mistura água e cravo para o balão de fundo redondo do sistema de destilação e usando a manta aquecedora, efetuou-se o aquecimento da mesma. Na ponta do aparelho destilador, o erlenmeyer recepcionou a solução proveniente da destilação, um líquido turvo, em virtude de ser uma mistura de óleo e solução aquosa. Ao fim do processo, a solução resultante foi colocada num funil de separação. Seguiu-se o processo, com a separação de fases, onde a solução contida no funil de separação divide-se em duas fases distintas. Nessa etapa, o funil de separação foi colocado em um suporte com argola metálica. Antes, com o funil tampado, agitou-se a solução em seu interior por três vezes consecutivas, com posterior liberação de vácuo contido no mesmo, repetida a cada etapa de agitação. Logo, por tratar-se de compostos orgânicos há constante pressão sendo exercida sobre o mesmo. Procedeu-se com a adição de $10 \mathrm{~mL}$ de Hexano medido em proveta, atuando como solvente da solução. Agitou-se a mistura, tomando sempre o cuidado de liberar a pressão do interior do recipiente. A solução permaneceu em repouso por alguns minutos, até que ocorresse a separação de fases. Em seguida, observou-se que a essência (o óleo) juntamente com o solvente concentrou-se na parte inferior do funil, e a solução aquosa na parte superior. A próxima etapa consistiu da extração da essência e adição de agente secante, onde o funil de separação tem a passagem de líquidos aberta de forma a liberar somente a fase concentrada na parte inferior do mesmo (óleo e solvente hexano). A solução foi recolhida em béquer, adicionou-se à mesma $5 \mathrm{~g}$ de sulfato de sódio, atuando como agente secante na solução. Seguindo com o procedimento, realizou-se a etapa de filtração, onde a solução foi imediatamente filtrada em funil de vidro com papel de filtro. A última etapa consistiu da evaporação e obtenção de essência. Nela, a solução proveniente da filtração foi colocada em um evaporador rotativo (Figura 2) para evaporar o solvente, obtendo-se a essência pura, que foi recolhida do balão com auxílio de uma pipeta Pasteur e armazenada, em recipiente apropriado. 


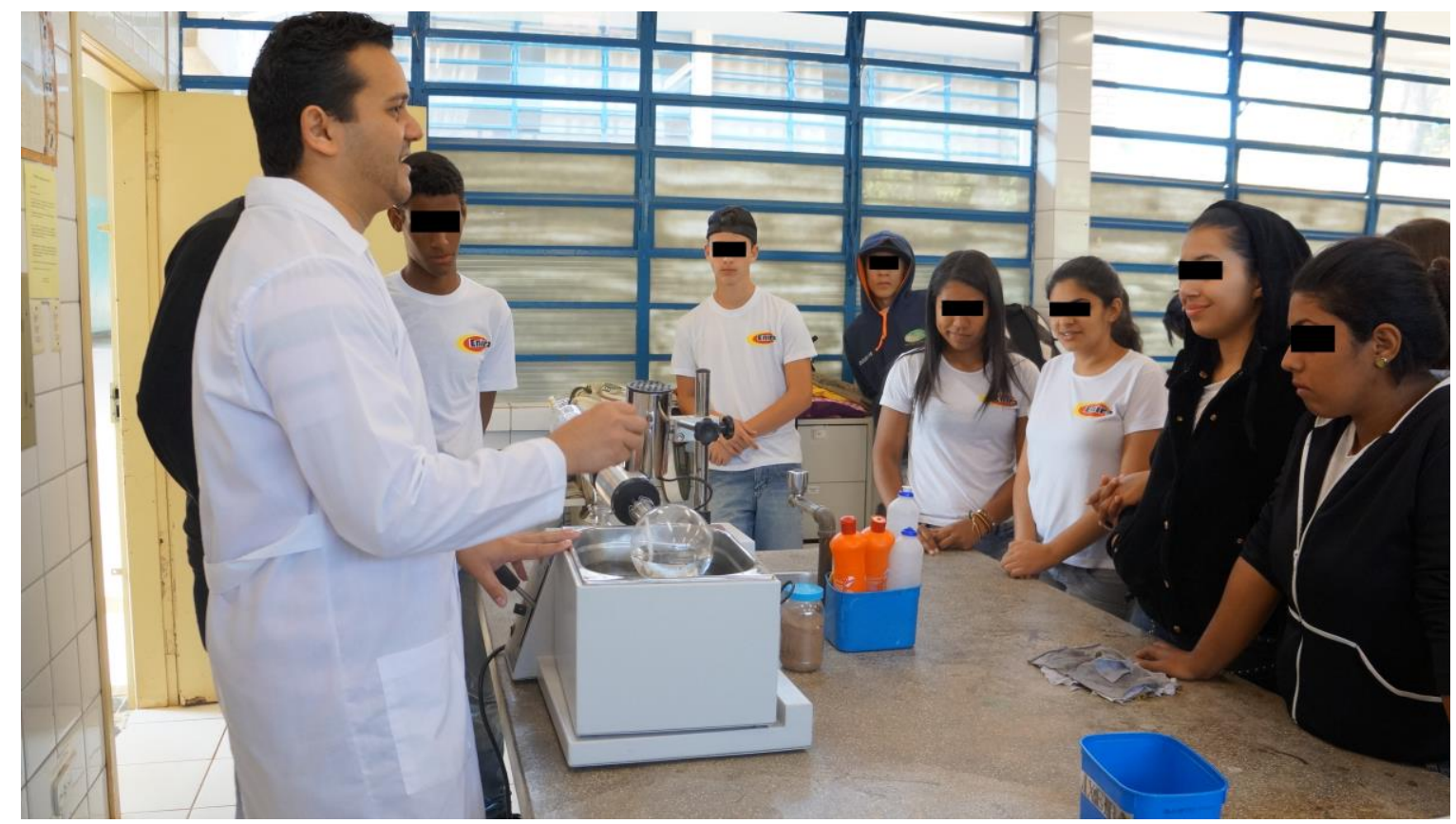

Figura 2 - Alunos do 3ํA do Ensino Médio prestando atenção na explicação do funcionamento do evaporador rotativo.

Fonte: Autor

\section{Resultados e discussões}

Foi notável observar ao longo da pesquisa o quanto os alunos se interessaram pelas aulas experimentais. Acompanharam atentamente todas as etapas da atividade, questionando sobre a aplicabilidade da prática na obtenção de óleos essenciais.

$\mathrm{Na}$ Figura 3 pode-se observar os resultados da pesquisa efetuada a partir do questionamento: o que você acha das aulas experimentais para o desenvolvimento dos conteúdos no ensino de química?

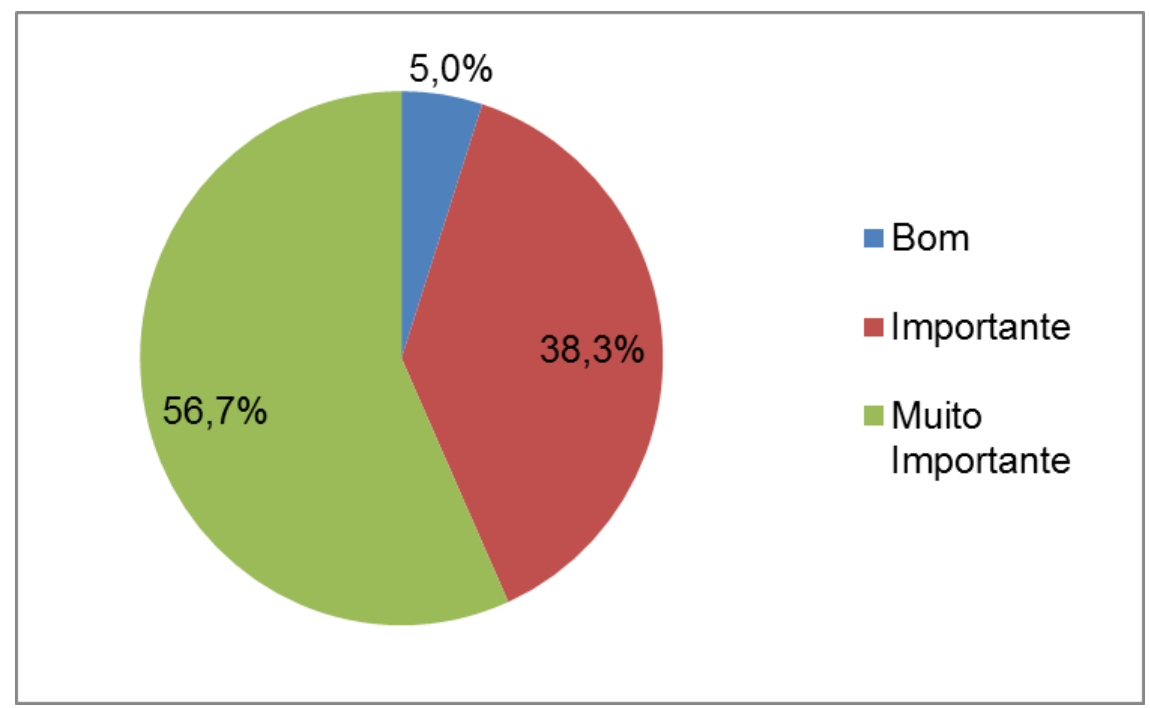

Figura 3 - Opinião dos Alunos com Relação às Aulas Experimentais no Ensino de Química.

Fonte: Autor 
Dos 60 alunos que participaram da pesquisa, 34 deles (56,7\%) acharam muito importantes, 23 alunos $(38,3 \%)$ responderam que foram importantes e $3 \%$ disseram que foram boas as atividades experimentais para a aprendizagem dos conteúdos químicos. Desta forma, percebe-se que a experimentação pode ser utilizada para discutir os conteúdos curriculares, assumindo um caráter construtivista quando os professores incentivam os alunos à percepção de conflitos cognitivos, que são motores da aprendizagem porque conduzem os alunos a buscar e confrontar informações, reconstruindo, assim, ideias e maneiras de explicar os conteúdos disciplinares.

No entanto quando o experimento é realizado somente com a intenção de que os alunos obtenham os resultados esperados pelo professor, quando não há problema algum a ser resolvido, e o aprendiz não é desafiado a testar suas próprias hipóteses ou encontrar inconsistência entre sua forma de explicar e a aceita cientificamente, a experimentação perde a sua característica principal: construção do conhecimento. Terá sido apenas uma forma de constatar a teoria e desprezar as divergências entre o que ele percebeu e o que acha que o professor espera que ele obtenha (CAVALCANTI et al., 2013).

A potencialidade da experimentação é destacada quando o aluno é convocado para elaborar hipóteses, testá-las, discuti-las, aprendendo sobre os conhecimentos químicos estudados e os conceitos científicos que os explicam, alcançando os objetivos de uma aula experimental, a qual privilegia o desenvolvimento de habilidades cognitivas e o raciocínio lógico. Durante as discussões, os alunos manifestaram que a experimentação desperta forte interesse pela disciplina proporcionando um caráter motivador, lúdico, essencialmente vinculado aos sentidos. Nesse aspecto, sobre motivação e aprendizagem, Tapia (2003) ressalta a necessidade de repensar a intenção de "motivar para aprender", pois talvez seja mais importante compreender que o sujeito precisa é "aprender para se sentir e manter-se motivado". Nessas condições, aprendizagem e motivação são constituintes de um contexto mais amplo que o das atividades experimentais, afirma 0 autor.

Além disso, alguns alunos relacionaram a atividade de laboratório com situações de reforço, facilitadoras da aprendizagem. Neste caso, as aulas práticas seriam atividades complementares, com as quais o estudante poderia contar quando tivesse dificuldades com a teoria. "Os alunos encontram reforço no processo à medida que avançam e verificam que o domínio de alguns conceitos lhes permitirá ir aprofundando e compreendendo a matéria objeto de estudo" (BARATIERI et al, 2008).

Em relação ao segundo questionamento: você acredita que a aula experimental sobre extração de óleo essencial de cravo-da-índia pode contribuir para melhorar a aprendizagem dos conteúdos da disciplina de química? foi respondida por 31 alunos da terceira série A e 29 alunos da terceira B. O resultado pode ser observado na Figura 4. 


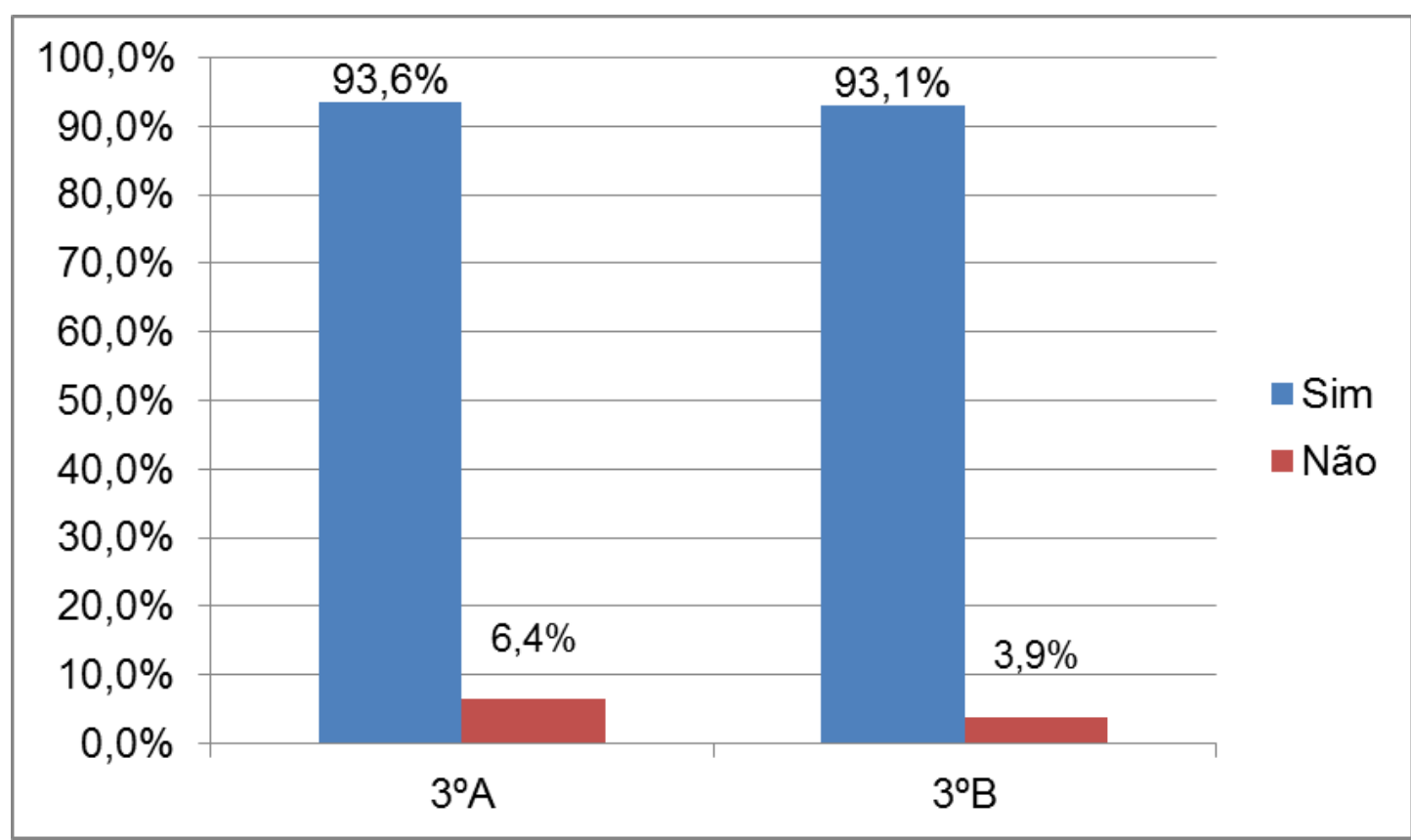

Figura 4 - Percentual de Alunos que Acreditam que a Aula Experimental sobre Extração de Óleo Essencial de Cravo-da-Índia pode contribuir para a aprendizagem da química.

Fonte: Autor

A análise das respostas dos alunos possibilitou constatar o seguinte: 93,6\% e $93,1 \%$ dos alunos, respectivamente das séries $A$ e $B$, expressaram que a extração do óleo essencial a partir do cravo-da-índia ajudou na construção de conceitos químicos, facilitando com a aprendizagem. Não se pode desconsiderar, portanto, o que escreve Lembo (1975): o que cada aluno precisa é de condições apropriadas e adequadas, condições necessárias para aprender e desenvolver-se. Percebe-se também que o aluno vê nas atividades experimentais uma forma de exercitar a resolução de problemas e de responder a questões que the são propostas pelos professores. $O$ acesso à explicação dos fatos não pode acontecer apenas em seus aspectos sensorial ou perceptivo, mas necessita ser construído pelo pensamento, portanto, abstratamente e expresso por meio de conceitos, portanto, teoricamente (FAZENDA, 2001).

Além disso, acreditamos que a aula experimental contribui muito para o enriquecimento dos conhecimentos químicos relacionado ao seu cotidiano, uma vez que a experimentação e a discussão dos resultados propiciam aos alunos a possibilidade de realizar, registrar, discutir com os colegas, refletir, levantar e avaliar as hipóteses e discutir com o professor todas as etapas do experimento.

Por outro lado, $6,4 \%$ dos alunos da Turma $A$ e $3,9 \%$ da turma $B$ responderam que a aula experimental não contribuiu para a aprendizagem de química. Neste sentido observamos que as respostas estão ligadas à dificuldade encontrada na aprendizagem de alguns conceitos realizados durante as atividades práticas de laboratório, falta de atenção, dificuldade de trabalho em grupo e até mesmo no desinteresse na elaboração dos relatórios sobre as atividades experimentais e também indiferença pela atividade escolar, não se restringindo apenas à atividade de laboratório. No entanto, a maioria dos alunos expressou claramente o quanto eles se motivaram e envolveram-se no processo de ensino-aprendizagem, construindo o conhecimento na interação com seus pares e com o professor. 
A pesquisa, como foi realizada, apresentando apenas duas questões também apresentou alguns limites. O instrumento de coleta de dados se permitiu uma análise fácil, não deixou explícitas as concepções mais aprofundadas dos participantes, o que, de certa forma, limitou a reflexão.

De acordo com Gonçalves e Marques (2006), a experimentação deve propiciar momentos de reelaboração dos conhecimentos, viabilizando o contato do aluno com fenômenos químicos, possibilitando ao aluno criar modelos explicativos sobre as teorias, utilizando uma linguagem própria.

Além de discutir as concepções dos alunos sobre atividades experimentais, mesmo que limitadas, a prática ofertada possibilitou abordar de maneira interdisciplinar vários assuntos como: estudo do habitat do cravo-da-índia, sua história, propriedades medicinais, indicações para saúde e princípios ativos.

$O$ estudo dos assuntos elencados foi realizado em forma de seminários, com a formação de quatro grupos de alunos, tanto na turma $A$ como na $B$, em que cada equipe ficou responsável pela pesquisa e apresentação dos resultados para todos os componentes da sala de aula.

Após a apresentação dos temas, o professor da disciplina promoveu uma discussão sobre os temas pesquisados pelos estudantes e elaboraram em conjunto um resumo destacando os principais resultados da pesquisa.

Discutiu-se ainda a constituição das essências, verificou-se as ligações e a funções químicas presentes em cada componente. Procurou-se assim, inserir alguns conceitos de funções orgânicas (como álcool, fenol, éter) e seus derivados.

Durante a apresentação das pesquisas pelos grupos, a maioria dos alunos procurou 'dar um palpite sobre o assunto' quando solicitado pelo professor, por apresentar questões mais simples do que as discussões sobre polaridade das ligações, funções orgânicas, entre outros, que exigem conhecimentos específicos de Química. Assim, na discussão de tais conhecimentos, foi necessária a intervenção mais marcante do professor da disciplina no sentido de construir o conhecimento na direção do que é cientificamente aceito e, portanto, dialogável com a comunidade científica (GIORDAN, 1999).

As atividades realizadas em grupo, de forma conjunta, ofereceram enormes vantagens, que não estão disponíveis em ambientes de aprendizagem individualizada. $O$ aprendizado e seus processos de pensamento ocorreram mediados pela relação com outras pessoas. Além disso, o trabalho colaborativo possibilitou, o resgate de valores como o compartilhamento e a solidariedade - que se foram perdendo ao longo do caminho trilhado por nossa sociedade, extremamente competitiva e individualista.

Segundo a reportagem "Educação científica: cenário de crise" (KUGLER, 2013), apenas $11 \%$ das escolas brasileiras tem laboratório de ciências. Esses fatos mostram 0 baixo investimento em aulas práticas fazendo com que os alunos apenas decorem a parte teórica sem realmente entender o que ocorre na prática. Apesar da escassez de atividades de laboratório, fato citado por vários pesquisadores, a atividade experimental pode estimular a curiosidade dos alunos, mas para isso, é necessário que estes sejam desafiados cognitivamente. Muitas vezes, a falta de estímulo demonstrado pelos alunos 
poderá ser um reflexo do tipo de aula utilizada pelo professor. Assim, a mera inserção dos adolescentes em atividades práticas não é fonte de motivação. É necessário que haja o confronto com problemas, a reflexão em torno de ideias inconsistentes por eles apresentadas.

\section{Considerações finais}

A potencialidade da experimentação é destacada quando o aluno é convocado para elaborar hipóteses, testá-las, discuti-las, aprendendo sobre os conhecimentos químicos estudados e os conceitos científicos que os explicam. Durante as discussões, os alunos concluíram que a experimentação desperta forte interesse pela disciplina proporcionando um caráter motivador, lúdico, essencialmente vinculado aos sentidos.

Assim, foi possível observar que a maioria dos alunos expressou claramente o quanto eles se motivaram e envolveram-se no processo de ensino-aprendizagem, construindo o conhecimento na interação com seus pares e com o professor. No entanto, os resultados obtidos neste trabalho mostram também a dificuldade encontrada por alguns alunos na aprendizagem de alguns conceitos realizados durante as atividades práticas de laboratório. Esses obstáculos poderiam ser descritos como falta de atenção, dificuldade de trabalho em grupo e até mesmo no desinteresse na elaboração dos relatórios sobre as atividades experimentais e também, na indiferença pela atividade escolar, não se restringindo apenas à atividade de laboratório.

Por outro lado, se as atividades práticas proporcionarem uma situação em um contexto de ensino e aprendizagem desenvolvendo tarefas de compreensão, interpretação e reflexão, distanciando-se do uso de prática descontextualizada, pode favorecer a mudança conceitual contribuindo para a construção de conceitos científicos. Pode-se afirmar ainda que as práticas permitem explorar outros conceitos envolvidos no fenômeno, assim como relacionar áreas do conhecimento, promovendo a interdisciplinaridade.

\section{Referências}

AXT, R. O papel da experimentação no ensino de ciências. In: MOREIRA, M. A; AXT, R. Tópicos em ensino de ciências. Porto Alegre: Sagra, 1991.

BARATIERI, S. M.; BASSO, N. R. de S.; BORGES, R. M. R.; ROCHA FILHO, J. B. da. Opinião dos estudantes sobre a experimentação em química no ensino médio. Experiência em Ensino de Ciências, v. 3, p. 19 -31, 2008.

BRASIL. Ministério da Educação (MEC). Secretaria de Educação Média e Tecnológica (Semtec). PCN + Ensino médio: orientações educacionais complementares aos Parâmetros Curriculares Nacionais - Ciências da Natureza, Matemática e suas Tecnologias. Brasília: MEC/Semtec, 2002.

Secretaria de Educação Fundamental. Parâmetros Curriculares Nacionais: Ciências Naturais / Secretaria de Educação Fundamental. Brasília: MEC/SEF, 2000.

Secretaria de Educação Fundamental. Parâmetros Curriculares Nacionais: Ciências Naturais / Secretaria de Educação Fundamental. Brasília: MEC/SEF, 1998. 
CARRASCOSA, J.; GIL-PÉREZ, D.; VILCHES, A.; VALDÉS, P. Papel de la actividad experimental en la educación científica. Caderno Brasileiro de Ensino de Física, v. 23, n. 2, p. 157-181, 2006.

CAVALCANTI, K.M.P.H.; SPRINGER, M.V., BRAGA, M. Atividades experimentais em Química através da metodologia de resolução de problemas. Anais... CONGRESO INTERNACIONAL SOBRE EDUCACIÓN, Girona, 2013.

CHALMERS, A.F. O Que é a Ciência Afinal? São Paulo: Brasiliense, 1993.

FAZENDA, I. Interdisciplinaridade: definição, projeto, pesquisa. In: FAZENDA, I. C. A. (Coord.). Práticas interdisciplinares na escola. 8 ed. São Paulo: Cortez, p.158, 2001.

FONSECA, M.R.M. Completamente química: química geral, São Paulo: Editora FTD, v. 2, 2001.

GALIAZZI, M. C., GONÇALVES, F. P. A Natureza Pedagógica da Experimentação: Uma Pesquisa na Licenciatura em Química. Química Nova, v. 27, n. 2, p. 326-331, 2004.

GIORDAN, M. O papel da experimentação no Ensino de Ciências. Química Nova na Escola. n. 10, p. 43-49, nov. 1999.

GONÇALVES, F.P.; MARQUES, C.A. Contribuições Pedagógicas e Epistemológicas em Textos de Experimentação no Ensino de Química. Investigação no Ensino de Ciências, v.11(2), p. $219-238,2006$.

HOFSTEIN, A.P.; LUNETTA, V. The laboratory science education: Foundation for the twenty-first century. Science Education, v. 88, p. 28 - 54, 2003.

KUGLER, H. Educação Científica: cenário de crise. Ciência hoje. 2013. Disponível em:<http://cienciahoje.uol.com.br/alo-professor/intervalo/2013/12/educacaocientifica-

cenario-de-crise >. Acesso em: 13 fev. 2015.

LEMBO, J. M. Por que falham os professores. São Paulo, SP: Editora P.U., p. $124,1975$.

LUCKESI, C.C. Avaliação da aprendizagem na escola: reelaborando conceitos e recriando a prática. Salvador: Malabares, 2003.

NANNI, R. A natureza do conhecimento científico e a experimentação no ensino de ciências. Revista Eletrônica de Ciências. São Carlos - SP, n. 24, 26 de maio de 2004. Disponível em: <http://cdcc.sc.usp.br/ciencia/artigos/art_26/natureza.html.> Acesso em: 11 mar. 2015.

PARANÁ. Secretária de Estado da Educação. Diretrizes Curriculares do Estado do Paraná. 2009. Disponível em: < http://www.educadores.diaadia.pr.gov.br/arquivos/File/diretrizes/dce_quim.pdf> Acesso em: 17 mar. 2015.

POSSOBOM, C. C. F.; OKADA, F. K.; DINIZ, R. E. da S. Atividades práticas de laboratório no ensino de biologia e de ciências: relato de uma experiência. 2002. Disponível em: <http://www.unesp.br/prograd/PDFNE2002/atividadespraticas. pdf $>$. Acesso em: 13 fev. 2015.

ROSITO, B. A. O ensino de ciências e a experimentação. In: SILVA, L. H. A. S.; ZANON, L. B. Construtivismo e ensino de ciências: reflexões epistemológicas e metodológicas. 2. ed., Porto Alegre: EDIPUCRS, 2003.

SCHNETZLER, R. P. A Pesquisa em Ensino de Química no Brasil: Conquistas e Perspectivas. Química Nova, v. 25, p.14, 2002. 
SILVA, L. H. A. S.; ZANON, L. B. Experimentação no ensino de ciências. In: SCHNETZER, R. P.; ARAGÃO, R. M. R. (Orgs.). Ensino de ciências: fundamentos e abordagens. Campinas: V Gráfica, p. 120 - 153, 2000.

TAPIA, A. Motivação e aprendizagem no ensino médio. In: COLL, $C$ et al. Psicologia da aprendizagem no ensino médio. Trad. Cristina M. Oliveira. Porto Alegre: Artmed, p.103 139, 2003.

TARDIF, M. Saberes docentes e formação profissional. Petrópolis: Vozes, 3. ed., 2002.

ZANON, L. B.; SILVA, L. H. A. A Experimentação no Ensino de Ciências. In: Schnetzler, R. P.; Aragão, R. M. R. (orgs.). Ensino de Ciências: Fundamentos e Abordagens. Capes/Unimep: Piracicaba, cap. 6, p.120 - 53, 2000.

Submissão: 08/10/2015

Aceite: 05/09/2017 